\title{
Rabies: Still with us
}

\author{
L Nicolle MD FRCPC
}

$\mathrm{R}$ abies is an important historical infectious disease. The frightening presentation and clinical course, with certain mortality from encephalitis, have excited attention and fear since the beginning of recorded history. Transmissibility of rabies from animals to humans was recognized long before the germ theory was entertained. Pasteur's dramatic experiment in 1885 is a legendary milestone in the treatment of infectious diseases (1). The use of postexposure prophylaxis with dried virus grown in rabbit spinal cords prevented rabies in a 12 -year-old boy who was bitten by a rabid dog. Postexposure prophylaxis progressed subsequently to phenol-inactivated rabies virus in 1919, which, while effective, was neurotoxic for one in 200 patients. This preparation was used for 50 years in North America, and continues to be used in some parts of the world (2).

Two papers in the present issue of The Canadian Journal of Infectious Diseases describe the most recent case of human rabies in Canada, which was diagnosed in Quebec in the summer of 2000. Despond et al (3) describe the case, and review clinical and epidemiological features of rabies illness in humans. Elmgren et al (4) provide a detailed description of the laboratory evaluation, including the genetic analysis of the infecting strain that confirmed origin from the silver haired bat (4). This is the first case of human rabies reported in Canada in 15 years, and one of only four that have been identified since 1970 . While human rabies is exceedingly uncommon in Canada, the dramatic clinical illness, uniform mortality and continuing risk ensure it remains a disease of continuing public health interest and attention.

Rabies is an uncommon illness in all developed countries. This is not a result of improved living conditions or socioeconomic status, but is a result of continuing programs to control zoonotic reservoirs. These include uniform vaccination of domestic animals, together with accessible and liberal use of postexposure prophylaxis following potential significant exposures. Widespread vaccination programs for terrestrial animals such as foxes, raccoons and coyotes have also contributed to control as zoonotic reservoirs of concern have shifted from domestic to wild animals $(5,6)$. Continuing surveillance of the disease in wild and domestic animal populations is ongoing across Canada. Pre-exposure vaccination for people who are at high risk, such as veterinarians and laboratory workers, is another component of rabies prevention. These programs are expensive and do not enjoy a high public profile, but the few cases of human rabies that occur in North America and other developed countries attest to their effectiveness.

Human rabies is more common in other parts of the world. In most developing countries, the majority of cases are still acquired as the result of a dog bite. Even in Mexico, domestic dogs are not vaccinated uniformly, and cases of disease have occurred following exposure to dogs (7). Rabies is a potential travel-acquired illness for Canadians who visit many other parts of the world.

The current management of rabies does not differ much from 100 years ago. Postexposure prophylaxis remains highly effective (8). The most important element in postexposure prophylaxis is wound care. Cauterizing of wounds caused by rabid animals was recommended until the middle of the 20th century. Now, thorough washing of the wound with a $20 \%$ soap solution and irrigation with a virucidal agent such as povidone-iodine are recommended, and may reduce subsequent disease by as much as $90 \%$. The important advance of the past 30 years is the development of safer vaccines. In North America, the human diploid cell, rhesus monkey diploid cell and purified chick embryo cell vaccines are now available. With the risk of postvaccination encephalomyelitis no longer a concern, more liberal use of postexposure prophylaxis is possible. Human or equine rabies immunoglobulin has also been introduced for high risk wounds, with current recommendations that the full dose should be infiltrated into the wound. While preven-

Health Sciences Centre, Department of Internal Medicine, Winnipeg, Manitoba

Correspondence: Dr LE Nicolle, Health Sciences Centre, Department of Internal Medicine, CG443-820 Sherbrook Street, Winnipeg, Manitoba R3A 1R9. Telephone 204-787-7029, fax 204-787-4826, e-mail nicolle@cc.umanitoba.ca 
tion is possible, antiviral treatment has not improved the outcome of disease when it occurs, although many agents have been tried (9).

This recent Canadian case highlights the risk of acquiring rabies in North America from bats. Most recent cases of human rabies in the United States and Canada have originated from bats (10). In fact, bats have been recognized as a source of rabies in America since the early 16th century. While patients with infection from zoonotic sources such as dogs, raccoons or skunks usually provide a clear bite history, patients with bat-acquired rabies frequently do not report a recognized exposure. In the case described in the present issue, bats were present in the bedroom of the patient, but no bite that could have precipitated postexposure prophylaxis was identified. This is similar to the American experience (10). The failure to identify a clear risk exposure with a bite or scratch raises the question of which bat contacts should initiate postexposure prophylaxis. Canada is a nation of cottage dwellers, and what cottage dweller has not had some experience with bats? Despond et al (3) confirm current recommendations that, if any bat exposure occurs for individuals who may not be able

\section{REFERENCES}

1. Pasteur L. Methods pour prevenur la rage apres morsure. CR Acad Sci 1885;101:765-72.

2. Plotkin SA. Rabies. Clin Infect Dis 2000;30:4-12.

3. Despond O, Tucci M, Decaluwe H, Gregoire M-C, Teitelbaum JS, Gurgeon N. Rabies in a 9-year-old child: The myth of the bite. Can J Infect Dis 2002;13:121-5.

4. Elmgren LD, Nadin-Davis SA, Muldoon FT, Wandeler AI. Diagnosis and analyses of a recent case of human rabies in Canada. Can J Infect Dis 2002;13:129-33.

5. Howe B, Swendrowski M, Fast M. Potential hazards of bat rehabilitation - Manitoba. Can Commun Dis Rep 1998;24:64-6. to provide a history of bites, such as young children or incapacitated adults, postexposure prophylaxis should be considered (8). This case certainly supports such a recommendation, but if followed uniformly and interpreted liberally, a substantial burden will be placed on public health resources. Certainly, a careful and repeated inspection for skin lesions that might be consistent with a bite should be undertaken, and postexposure prophylaxis should be encouraged if any suggestive lesions are identified.

What do we learn from the first case of human rabies in Canada in 15 years? First, it reminds us of how uncommon rabies is in this country and how successful control programs have been. It also focuses concern on the challenge of prevention of transmission of bat rabies to humans. Do all Canadians recognize the potential danger of bat exposure? The Canadian public, particularly rural dwellers, need to be informed of possible risks, recommendations for immediate wound care, and how to access postexposure prophylaxis. Finally, this is a humbling reminder of an important historical infectious disease that remains as devastating clinically today as it was 5000 years ago, despite our great progress in microbiology and therapeutics.

6. Rupprecht CE, Hanlon CA, Niezgoda M, et al. Recombinant rabies vaccines; Efficacy assessment in free-ranging animals. Onderstepoort J Vet Res 1993;60:463-8.

7. Doyle TJ, Bryan RT. Infectious disease morbidity in the US region bordering Mexico, 1990-1998. J Infect Dis 2000;182:1503-10.

8. Health Canada. Rabies. Canadian Immunization Guide, 5 th edn. Ottawa: Health Canada, 1998.

9. Dutta JK, Dutta TK. Treatment of clinical rabies in man. Drug therapy and other measures. Clin Pharmacol Ther 1994;32:594-7.

10. Noab DL, Drenzek CL, Smith JS, et al. Epidemiology of human rabies in the United States, 1980-1996. Ann Intern Med 1998;128:922-30. 


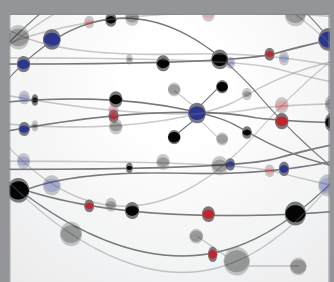

The Scientific World Journal
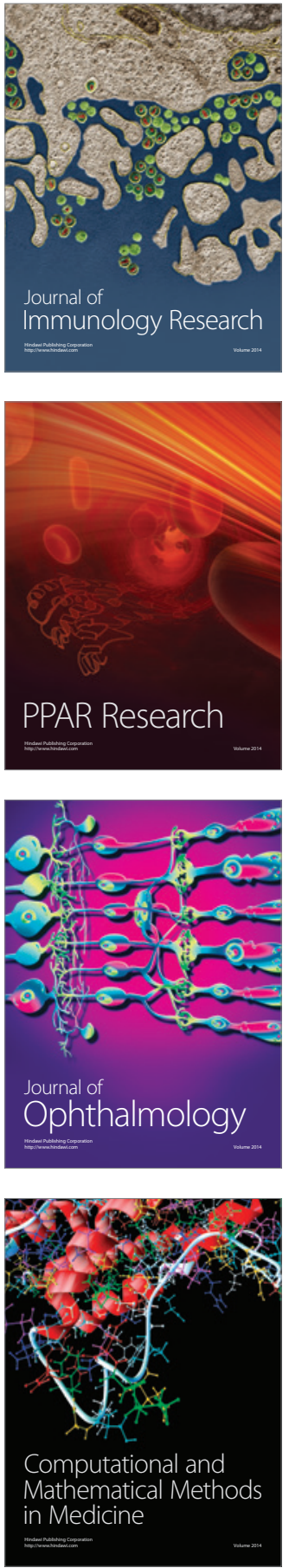

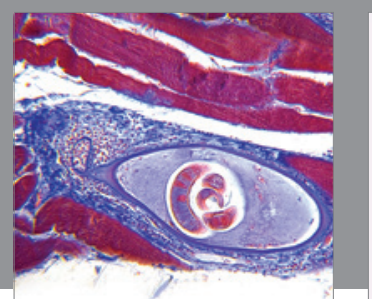

Gastroenterology Research and Practice

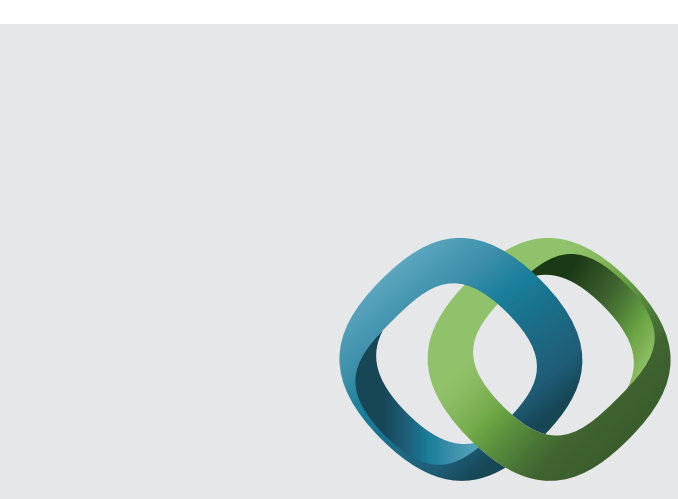

\section{Hindawi}

Submit your manuscripts at

http://www.hindawi.com
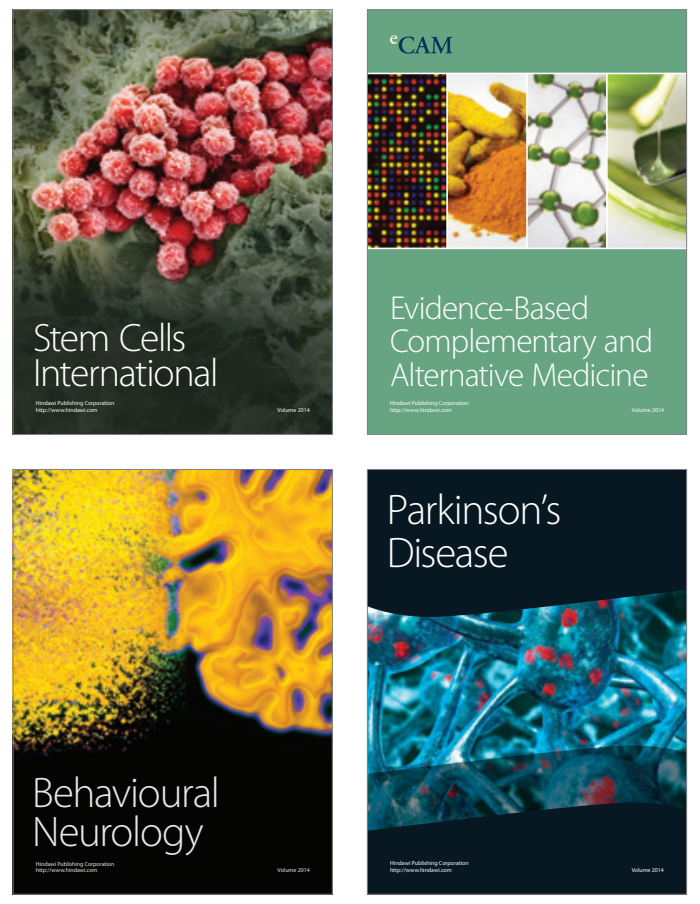
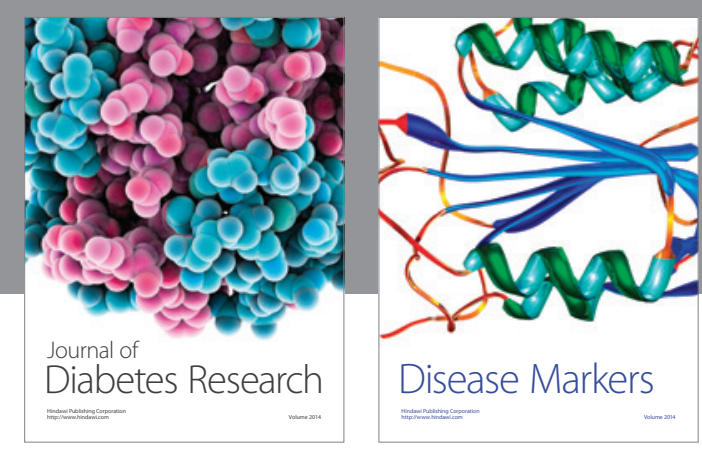

Disease Markers
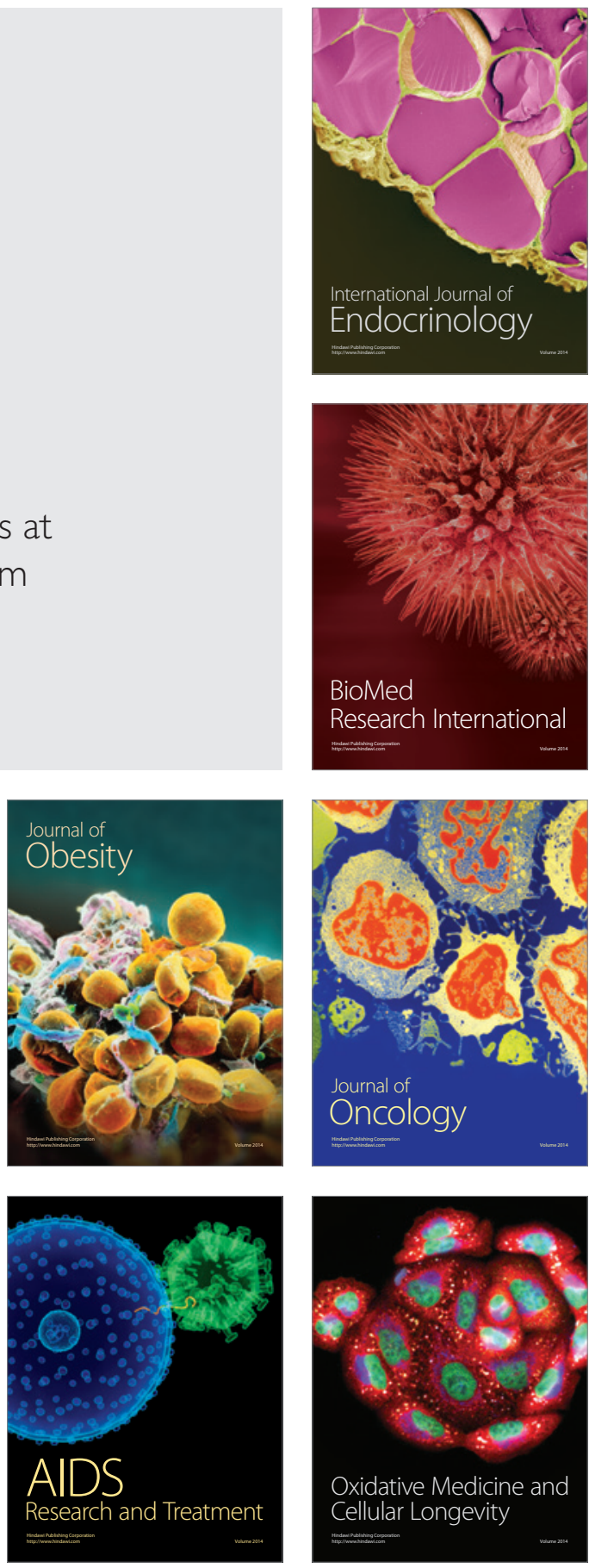